\title{
Adjusting the Influence Function Method for Subsidence Prediction
}

\author{
Ali Saeidi ${ }^{1, a}$, Olivier Deck ${ }^{2, b}$, Marwan Al Heib ${ }^{3, c}$, \\ Thierry Verdel $^{2, \mathrm{~d}}$ and Alain Rouleau ${ }^{1, \mathrm{e}}$
}

${ }^{1}$ Centre d'études sur les ressources minérales, Université du Québec à Chicoutimi, 555 boulevard de l'Université, Chicoutimi (Québec), Canada, G7H

\author{
${ }^{2}$ Laboratoire Environnement Géomécanique \&Ouvrages, Campus ARTEM, Rue du Sergent \\ Blandan 54042 Nancy \\ ${ }^{3}$ LAEGO-INERIS Campus ARTEM - Rue du Sergent Blandan 54042 Nancy \\ aali_saeidi@uqac.ca, bolivier.deck@mines.inpl-nancy.fr, 'Marwan.ALHEIB@ineris.fr, \\ thierry.verdel@mines.inpl-nancy.fr, ${ }^{\mathrm{A} A l a i n \_R o u l e a u @ u q a c . c a}$
}

Keywords: Mining subsidence, Influence function method, vertical subsidence, influence angle.

\begin{abstract}
The extraction of ore and minerals by underground mining may induce ground subsidence phenomena. These phenomena produce several types of ground movement like horizontal and vertical displacements, ground curvature and horizontal ground strain at the surface, and associated building damage in urban regions. The influence function is a well-known and efficient method for the prediction of these movements, but its application is restricted to mining configurations with the same influence angle around the mine. However, this angle may display different values when the mine is not horizontal or when other subsidence events already occurred near the considered mine.

In this paper a methodology and an algorithm are developed, based on the traditional influence function method in order to take into account different influence angles. This methodology is implemented in the Mathematica software and a case study is presented with data from the Lorraine iron mine field in France. Ground movements calculated with the developed methodology show a fair concordance with observed data.
\end{abstract}

\section{Introduction}

The extraction of ore and minerals by underground mining may induce ground subsidence. These phenomena produce several types of ground movement: horizontal and vertical ground displacements, ground curvature and horizontal ground strain at the surface [1]. These movements can cause damage to buildings and infrastructures on the surface, and jeopardise the safety of people. Therefore, predicting ground subsidence is very important in regions with underground mining, and several prediction methods have been developed. These methods can be classified into empirical, semi-empirical and numerical methods. The empirical and semi-empirical methods include graphical methods, profile function methods and influence function methods [2].

Numerical methods include finite element, distinct elements and finite differences methods. These methods can be very accurate when validated, but their application at a specific site and or in a certain context is highly dependent on the available data regarding the local geology, the mechanical properties of the overburden and sub-surface rock/soil. Moreover calculating a three dimensional prediction of the subsidence may require a large computational effort [3].

Graphical methods are derived from analysing an extensive field database collected over many years from mining subsidence in one mining area. A disadvantage of these methods is that they are developed in relation to a specific context and cannot be used with accuracy in other contexts. A well-known example has been developed by the NCB [4], which has provided several abacuses that can be used to predict subsidence for simple mine geometry (rectangular). 
The profile function methods are based on mathematical functions that have been obtained by a curve fitting procedure to match the predicted profile with observed profiles [5]. Many profile functions are available for subsidence prediction [4].

Influence function methods (IFMs) were developed by Ren et al. 1987 [6] and are used extensively [5,7] to predict mining subsidence. They are based on the superposition principle and consider the displacements induced by a subsidence at a given point as the sum of the displacements induced by the subsidence of elementary mining units. IFM methods present several advantages compared to other methods for the three dimensional prediction of subsidence. First, these methods can be used with any type of mine geometry; empirical and semi-empirical methods are restricted to simple geometries. Secondly, these methods can be used to simultaneously assess vertical and horizontal ground movements induced by the subsidence at each point of the surface. In particular, the horizontal ground strain can be calculated everywhere and then used to assess the building damage $[5,7,8,9]$.

However, IFMs are developed with consideration of the same influence angle for all edges of a mine panel, while several influence angles are often observed in mining engineering. For example in the Lorraine iron basin the influence angle depends on the nature of the ground beyond the boundary of each edge of the mine polygon [10]. Therefore traditional IFMs cannot be used for prediction or calculation of subsidence in these regions.

This paper describes a methodology for applying the IFMs in the case of several influence angles. First, the principles of IFMs are explained, then the methodology is developed for the case of the several influence angles. A final section shows an application and final test of the methodology with a case study in the Lorraine iron basin.

\section{Prediction of the subsidence parameters}

This method is based on the superposition principle and addresses the displacements induced by a subsidence at a given point as the sum of the displacements induced by the subsidence of elementary mining units.

Assuming an infinitesimal element dA (Fig. 1) at depth $\mathrm{H}$ to be extracted, the element will create an elementary trough at the ground surface. The deepest point of the trough is located directly above the extraction element $\mathrm{dA}$, and the depth of the trough decreases with the radial distance from the deepest point. Consequently, the subsidence of a point $\mathrm{P}$ can be stated as a function of the radial distance between $\mathrm{P}$ and the trough central point.

The elementary subsidence $\mathrm{dS}_{\mathrm{z}}$ caused by an elementary surface $\mathrm{dA}$ at a point on the ground surface is calculated with Eq. 1.

$$
\mathrm{dS}_{\mathrm{z}}=\mathrm{S}_{\max } \times \mathrm{K}_{\mathrm{z}}(\mathrm{r}) \times \mathrm{dA}
$$

Where $S_{\max }$ is the maximum value of subsidence that can be observed for a critical and super critical case (i.e. for mines with a width greater than $2 \mathrm{Htan} \gamma), \mathrm{K}_{z}(\mathrm{r}, \gamma)$ is the influence function, $\mathrm{r}$ is the radial distance between the surface $\mathrm{dA}$ and the ground surface point under consideration, and $\gamma$ is the influence angle (Fig. 1).

The total vertical subsidence at a given point $\mathrm{P}$ on the ground surface can then be estimated by integrating Eq. 1 over the mine panel surface (A) (Eq. 2).

$$
S_{z}=S_{\max } \iint_{A} K_{z} \times d A
$$

An equivalent and frequent calculation of the subsidence considers a cone of influence whose apex is located at the point considered of the ground surface (Fig. 2). In this figure, we consider a point on the ground surface and calculate the effect of all elements of the mine surface contained in the cone of influence. For example, Fig. 2a shows three unit areas of the mine under the point $\mathrm{P}$ on the surface. The influence of the element is maximal for $\mathrm{dA}_{1}$, which is located in the centre of the cone under the point $\mathrm{P}$, the influence of the element $\mathrm{dA}_{2}$ is less than that of the $\mathrm{dA}_{1}$, and the $\mathrm{dA}_{3}$ element 
has no influence at the point $\mathrm{P}$ [5]. This methodology requires discretising the surface area of the cone base into several rings and sectors (Fig. 2b and c). The calculation of the subsidence for each point $\mathrm{P}$ on the ground surface requires applying Eq. 1 to all of the sectors of the mine area included into the cone of influence under the point $\mathrm{P}$ [5].

$$
S=\sum d s
$$

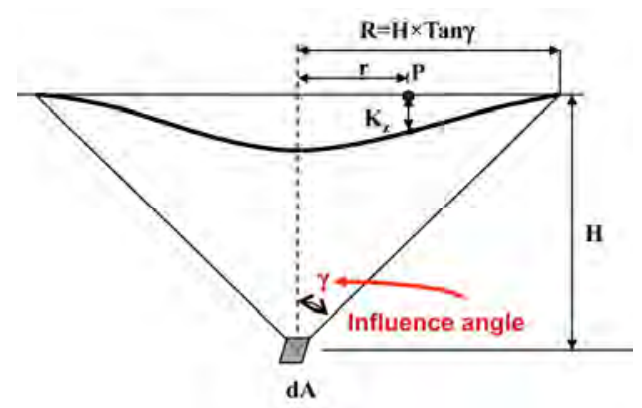

Fig. 1 Principle of the influence function method. An infinitesimal mining element dA at depth $\mathrm{H}$

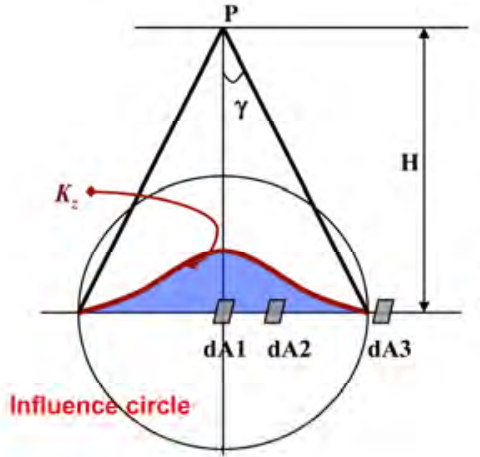

(a)

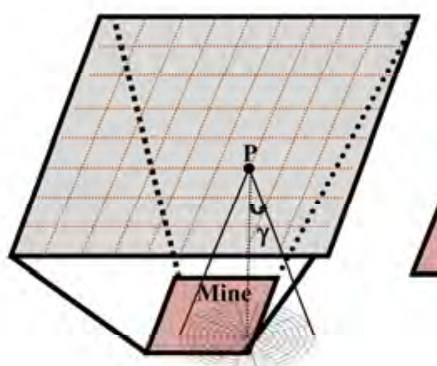

(b)

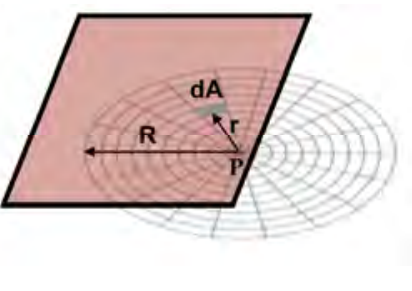

(c)

Fig. 2 (a) Illustration of the influence of an elementary area $\mathrm{dA}_{\mathrm{i}}$ on the subsidence of a given point

$\mathrm{P}$ on the surface. (b) Discretisation of the cone surface base into several rings and sectors. (c) Calculation of subsidence due to each sector dA.

A numerical software is developed to calculate subsidence parameters at any point of the ground surface $(\mathrm{P})$. An application of this software to a theoretical rectangular mine is illustrated in Fig. 3 as an example. The geometrical dimensions are shown in Fig. 3a; a mine depth of $120 \mathrm{~m}$ and an influence angle of $35^{\circ}$ are considered. The results of vertical subsidence are presented as isovalues (Fig. 3a) and in a profile in a X-X vertical section (Fig. 3b).

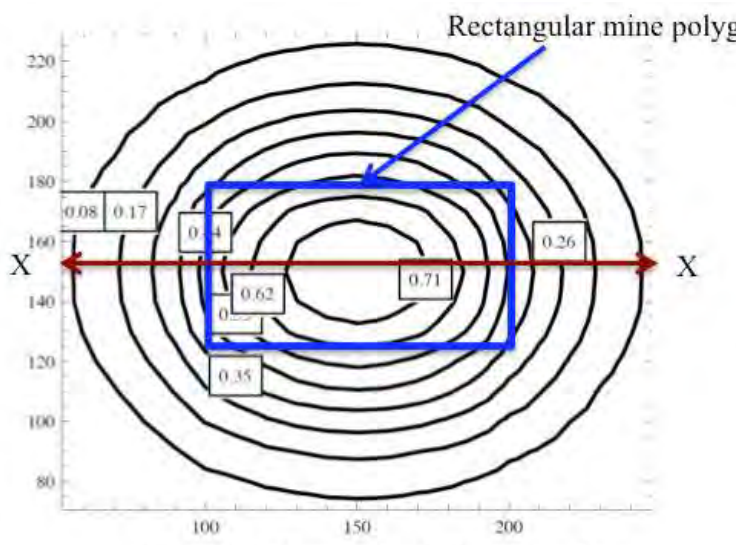

a) Isovalu of vertical subsidence vertical

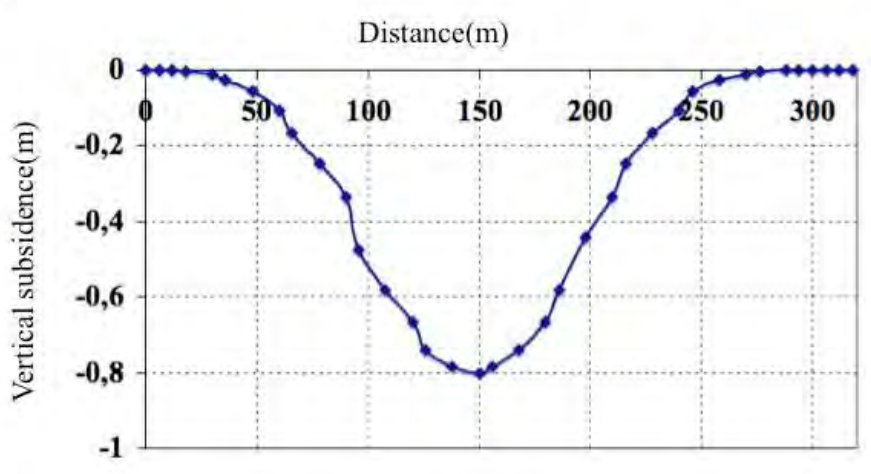

b) X-X section

Fig. 3. Illustration of results obtained by the IFMs for a rectangular mine, with a) contours of vertical subsidence; and b) subsidence profiles for vertical section in direction X-X. 


\section{Application of IFMs in the case of several values of the influence angle}

IFMs methods are usually developed while considering the same value of influence angle for all edges of the mine panel. However, influence angles may vary around a mine panel. This is the case in the French Lorraine iron-ore basin, where the influence angle depends on the nature of the ground beyond the boundary of each edges of the mine polygon. The study in this basin [10, 11] shows that if the adjacent ground is intact (i.e without mine workings) then the influence angle is about 10 degrees. If the adjacent ground has been excavated for mining, the influence angle is larger and varies with the method that was used for mining (Table 1). Two different methods of estimating the influence function considering different values of the influence angle are proposed in this paper.

Table 1. The values of influence angle depending on the nature of ground at the boundary of each edge.

\begin{tabular}{|l|c|c|c|}
\hline $\begin{array}{l}\text { Nature of ground beyond } \\
\text { each edge boundary. }\end{array}$ & $\begin{array}{c}\text { Intact or unexcavated } \\
\text { area }\end{array}$ & $\begin{array}{c}\text { Rooms and pillars } \\
\text { area }\end{array}$ & $\begin{array}{c}\text { Collapsed or } \\
\text { subsided area }\end{array}$ \\
\hline Influence angle $\left(^{\circ}\right)$ & $0-10$ & $6-29^{\circ}$ & $23-40^{\circ}$ \\
\hline
\end{tabular}

\section{Estimating the influence function - Method A}

Method A applies a technique that assigns an influence angle value of a given point $\mathrm{P}$ at the ground surface (Fig. 4a) as being equal to the characteristic influence angle of the nearest edge of the polygon. Considering for example a rectangular mine polygon with four different values of influences angle (Fig. 4a), we can see that for point A of the ground surface the influence angle is $\gamma_{3}$, because this point is closer to the edge of the polygon, which characteristic influence angle is $\gamma_{3}$. Similarly, for the point B, the influence angle is $\gamma_{4}$ (Fig. 4a).

Considering that the perpendicular line is the minimum distance between a point and a line, the line equation of each edge of polygon is calculated using Eq. 4:

$$
Y-y_{1}=\frac{y_{2}-y_{1}}{x_{2}-x_{1}}\left(X-x_{1}\right)
$$

with $\left(\mathrm{x}_{1}, \mathrm{y}_{1}\right)$ and $\left(\mathrm{x}_{2}, \mathrm{y}_{2}\right)$ the coordinates of two points of a same polygon edge.

If the line equation is written as $\mathrm{Ax}+\mathrm{By}+\mathrm{C}=0$, the perpendicular distance of a point $\mathrm{A}$ with coordinates $\left(\mathrm{x}_{\mathrm{A}}, \mathrm{y}_{\mathrm{A}}\right)$ is defined by Eq. 5 (Fig. $\left.4 \mathrm{~b}\right)$ :

$$
d=\frac{\left|A \cdot x_{A}+B y_{A}+C\right|}{\sqrt{A^{2}+B^{2}}}
$$

This technique gives inconsistent results as shown in Fig. 4b. The influence angle assigned to point $\mathrm{P}$ is $\gamma_{4}$ because the length of "PC" is less than the length "PD" while the consistent influence angle is more logically $\gamma_{3}$. The technique is then modified as follows: each polygon edge is discretized into several small segments with characteristic mean coordinates $\left(\mathrm{X}_{\mathrm{i}}, \mathrm{Y}_{\mathrm{i}}\right)$. Then the distance of the given point $\mathrm{P}$ with $\left(\mathrm{X}_{\mathrm{p}}, \mathrm{Y}_{\mathrm{p}}\right)$ coordinates and each characteristic point with $\left(\mathrm{X}_{\mathrm{i}}, \mathrm{Y}_{\mathrm{i}}\right)$ coordinates are calculated with Eq. 6.

$$
d_{i}=\sqrt{\left(X_{p}-X_{i}\right)^{2}+\left(Y_{p}-Y_{i}\right)^{2}}
$$

Then the minimum distance $\mathrm{d}_{\mathrm{i}}$ is determined (Eq. 7) and the influence angle related to this segment is considered as the influence angle of point $P$.

$$
\gamma_{p}=\gamma_{i} \in\left(d_{i}, \gamma_{i}\right) \text { if } \mathrm{d}_{\mathrm{i}} \text { is minimum }
$$


For example, in Fig. 4c the smallest segment among PE, PG, PH, PK, PL is PH and the influence angle assigned to the point $\mathrm{P}$ is $\gamma_{3}$.

The influence angle related to each point of the ground surface is first calculated with this method, then the subsidence parameters could be calculated for each one of these surface points.

This method of considering different influence angles is tested with a rectangular polygon (Fig. 5). Two influence angle values are considered $\left(20^{\circ}\right.$ and $\left.35^{\circ}\right)$ for the opposite edges. Other characteristics are: $\mathrm{S}_{\max }=1.4 \mathrm{~m}, \mathrm{H}=120 \mathrm{~m}$, the dimension is $50 \mathrm{~m} \times 100 \mathrm{~m}$.

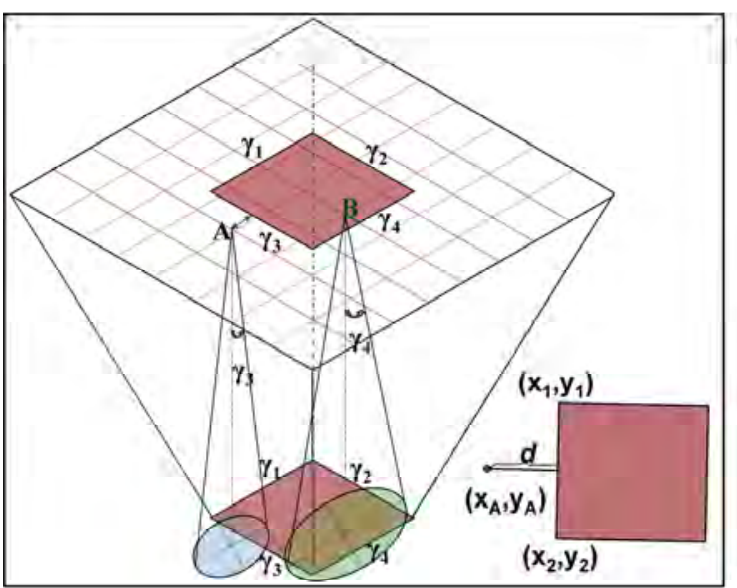

(a)

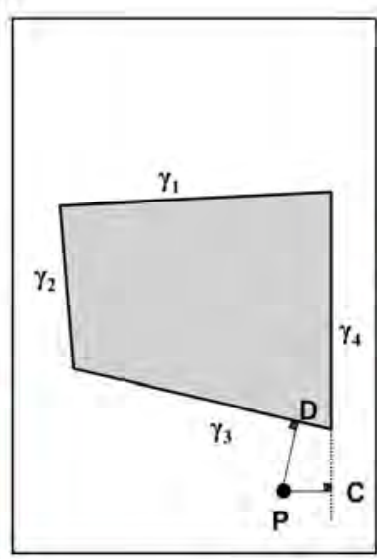

(b)

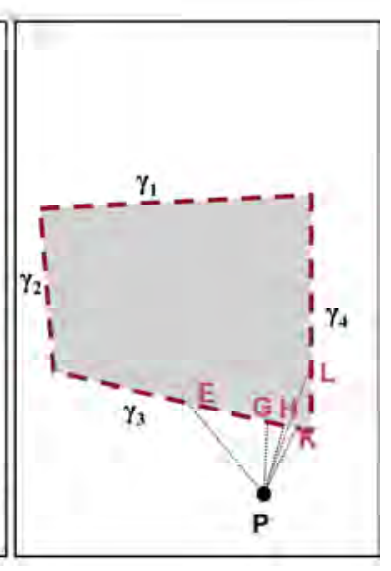

(c)

Fig. 4. a)Method A for calculatng the influence angle of each point of the ground surface. $b$ ) Selecting the influence angle for each point of ground surface. c) ) Selecting the influence angle for each point of ground surface.

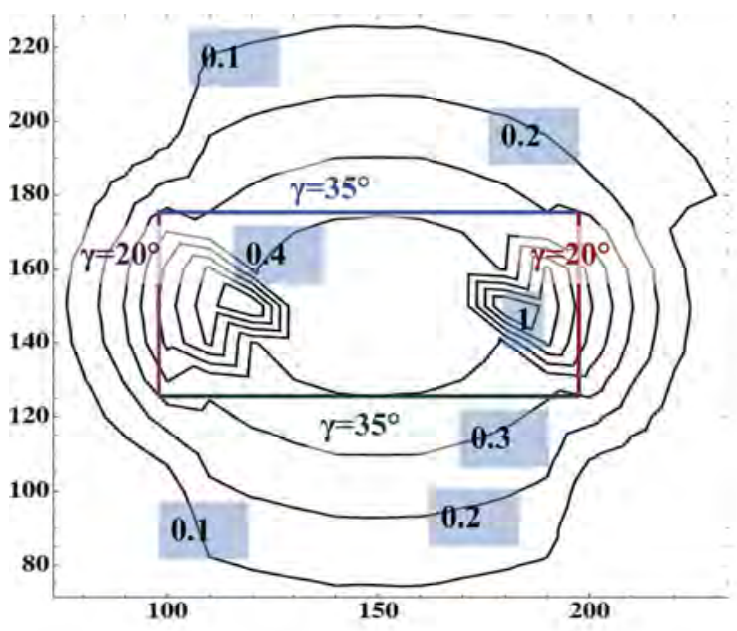

(a)

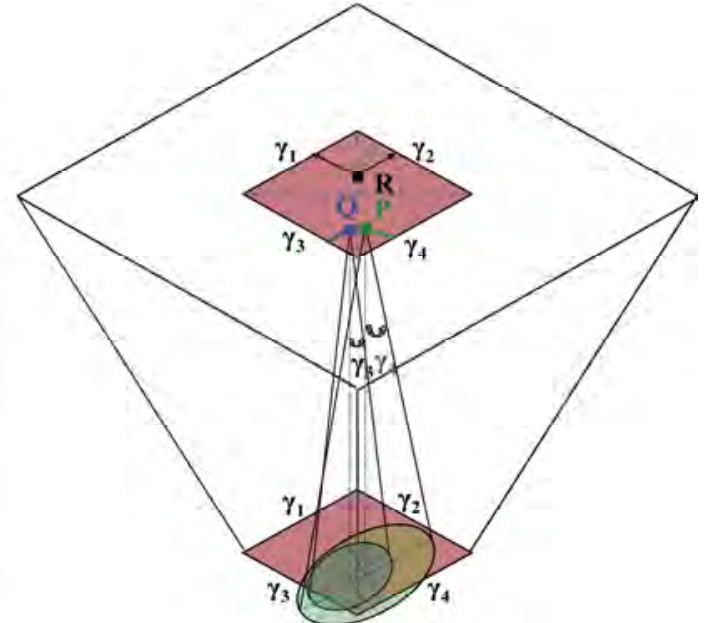

(b)

Fig. 5. Contours of the vertical subsidence in the case of different influence angle for a square mine and (b) Identification of problems in selecting an influence angle by the methodology of the nearest edge.

Results presented in Fig. 5a are not realistic because of significant discontinuities. These are explained by a threshold effect shown in Fig. 5b, where it is observed that for two closely located points $\mathrm{P}$ and $\mathrm{Q}$, the influence angle can be considered different (20 and 35 degrees), which is not realistic. Moreover, the $\mathrm{R}, \mathrm{S}$ and $\mathrm{T}$ points illustrate the cases of indeterminate points as they are located equidistant between two polygon edges of the mine. 


\section{Estimating the influence function - Method B}

For solving the discontinuity problem, a different method is proposed to calculate the influence function. In this case, the apex of the cone of influence is located at the mine level. The algorithm of this method is summarized in Fig. 6a.

The polygon of the mine is discretized into a large number of elementary surfaces (Fig. 6b). Each elementary surface is then considered as a small polygon of mine with a constant influence angle for which it is possible to apply the IFMs. A value of the influence angle is then assigned to each elementary surface of the mine, according to the nearest edge, which allows calculatingthe displacement induced on all points of the ground surface.

The displacements induced by the rectangular mine shown in Fig. 5b (Fig. 7) have been calculated. The results appear realistic as they do not show any discontinuity. It is observed that the maximum vertical subsidence in two regions near the edges is characterized by low values of the angle of influence.

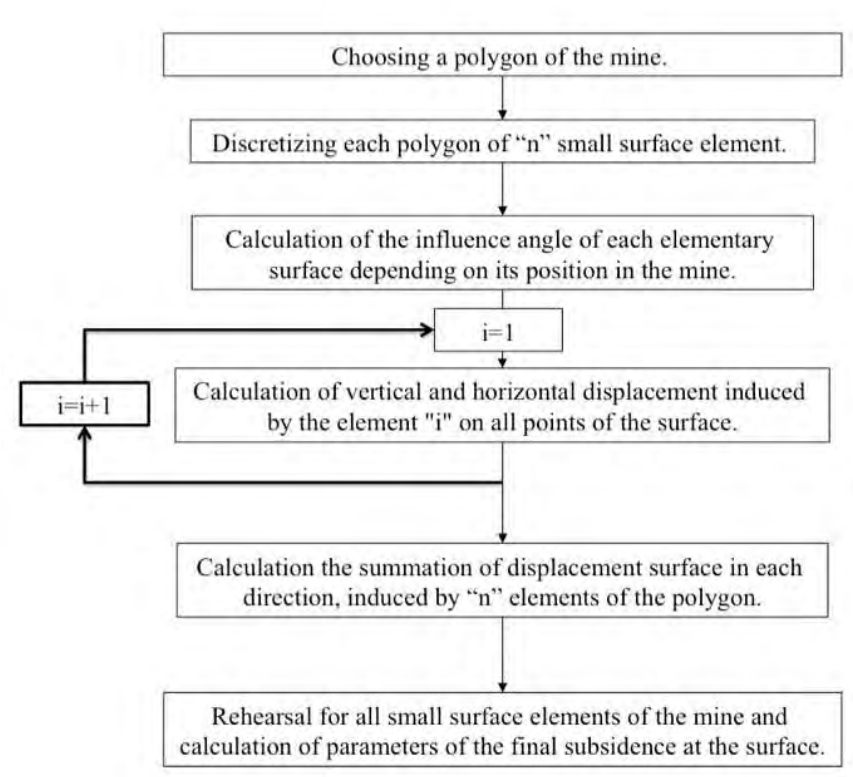

(a)

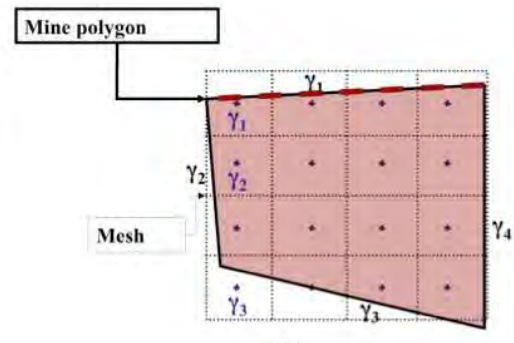

(b)

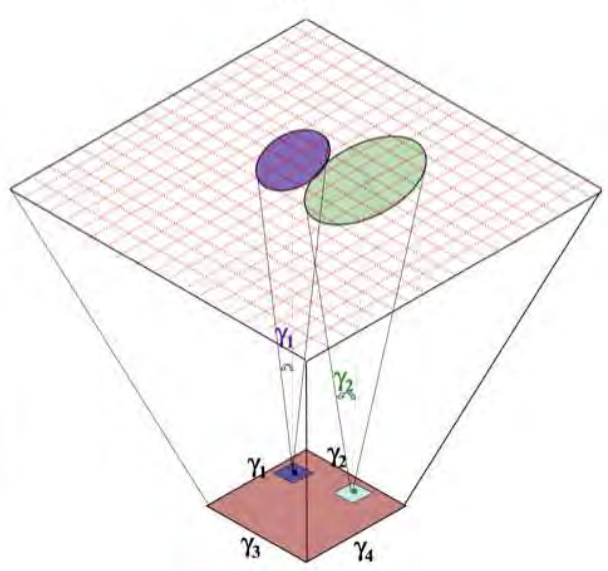

(c)

Fig. 6. Details of method B to take into account different influence angles. a) algorithm of the method, b) definition of the angle of influence of each small surface in the mine polygon, c) effect of each small mine surface on the ground surface.

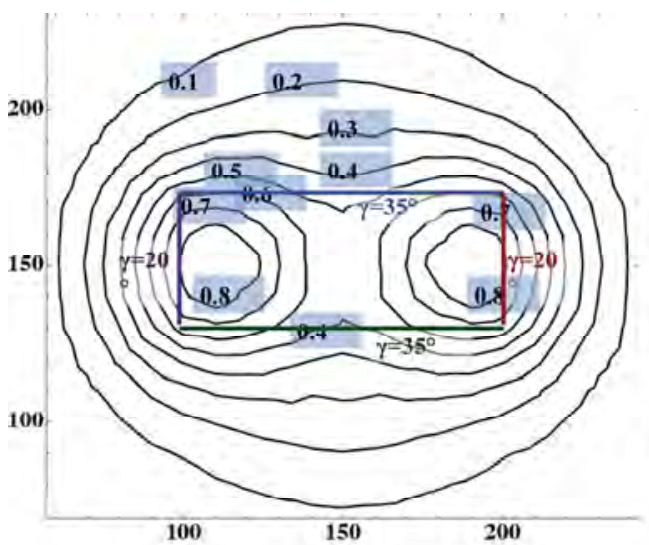

(a)

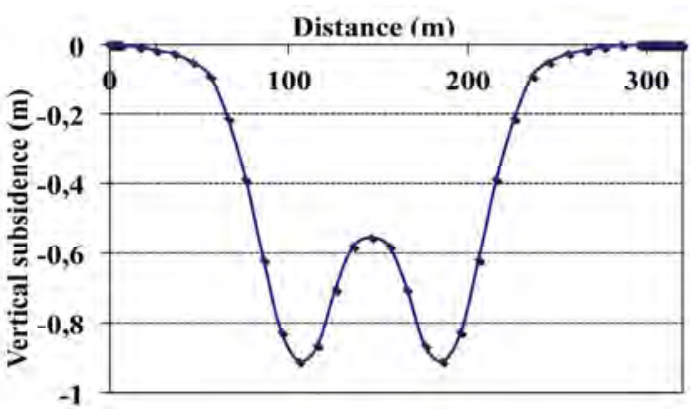

(b)

Fig. 7. a) Contoure of vertical subsidebce b) Vertical subsidence section in A-A Direction. 


\section{Application and validation of methodology}

In France, the Lorraine region displays a very large number of old underground mines excavated using the room and pillars technique under urbanized areas. Between 1996 and 1999, five subsidence events occurred (two in the city of Auboué in 1996, two in Moutiers in 1997, and the last one in Roncourt in 1999) which caused damage to more than 500 dwellings. In this paper we consider the Roncourt case for verification and validation of our model.

Isovalues of the observed vertical subsidence and a vertical section of this parameter in the direction $\mathrm{AB}$ are shown in Fig. 8. The polygon of the collapsed mine (collapsed area based on several measurements and tests performed by INERIS [12]) with different values of the influence angles are shown in Fig. 8b. The characteristics are specified in Table 2, where the points $\mathrm{P}_{\mathrm{i}}$ are the coordinates of the polygons, $\mathrm{O}$ is the opening of the mine, $\tau$ is the extraction ratio and $\mathrm{H}$ is the depth of the mine. The calculated values of the subsidence are shown in Fig. 8b, and can be compared with observed values in Fig. 8d. Comparing the results with measurements (Fig. 8d) is satisfactory considering the various uncertainties affecting the data and the model.

Table 2. Characteristics of mine polygon in Roncourt mine ([12]).

\begin{tabular}{|c|c|c|c|c|c|c|c|}
\hline & $\mathrm{P}_{1}[\mathrm{~m}]$ & $\mathrm{P}_{2}[\mathrm{~m}]$ & $\mathrm{P}_{3}[\mathrm{~m}]$ & $\mathrm{P}_{4}[\mathrm{~m}]$ & $\mathrm{O}[\mathrm{m}]$ & $\tau$ & $\mathrm{H}[\mathrm{m}]$ \\
\hline Polygon 1 & $(434,406)$ & $(495,601)$ & $(327,538)$ & $(289,418)$ & 2,5 & 0,53 & 140 \\
\hline Polygon 2 & $(557,537)$ & $(572,627)$ & $(497,607)$ & $(468,515)$ & 2,5 & 0,53 & 140 \\
\hline
\end{tabular}
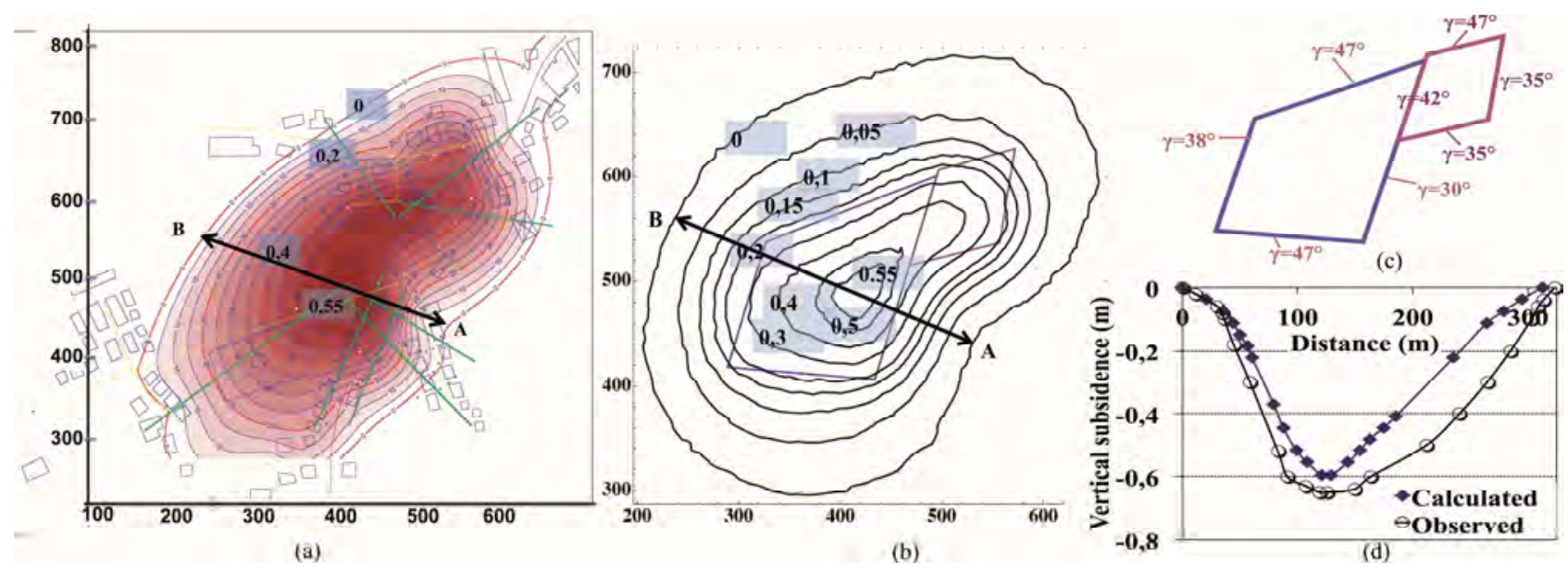

Fig. 8. Comparison of observed results at the site of Roncourt with the predicted results given by the modified influence functions method.

\section{Conclusion}

The influence function methods with suitable modifications can be used to predict subsidence for mine panels, even for panels with complex geometry. However these methods are developed for mine panels with a characteristic influence angle that has the same value over the entire mine workings. In a number of field cases, such as the iron mining area in Lorraine, different values of influence angle must be considered over a mine. A methodology is developed to apply IFMs over a mine site considering a variable influence angle in order to assess the ground subsidence.

This methodology is implemented in the Mathematica software and a case study is presented with data of the Lorraine iron mining area in France. Ground movements calculated with the developed methodology are compared with the observational data and show a fair concordance. 


\section{References}

[1] O. Deck, T. Verdel, and R. Salmon: Vulnerability assessment of mining subsidence hazards. Risk Analysis, 19(10) (2009) p. 1381-1394.

[2] K. Aissaoui: Amélioration de la prévision des affaissements dans les mines à l'aide des approches empiriques, numériques et analytiques. Thèse de doctorat, Institut National Polytechnique de Lorraine, Nancy (1999.)

[3] A.R Alejano, P. RamõÂrez-Oyanguren and J. Taboada: FDM predictive methodology for subsidence due to flat and inclined coal seam mining. International Journal of Rock Mechanics and Mining Sciences, 36 .(1999), p. 475-491.

[4] National Coal Board: Subsidence engineering handbook. (1975).

[5] B.N Whittaker, D.J Reddish: Subsidences : Occurrence, Prediction, Control. Elsevier, (1989)

[6] G. Ren, D.J Reddish, and B.N Whittaker: Mining subsidence and displacement prediction using influence function method. Min Sci Tech. 5 (1987): 89-104.

[7] P.R Sheorey, J.P Loui , K.B Singh, S.K Singh: Ground subsidence observations and a modified influence function method for complete subsidence prediction. International Journal of Rock Mechanics and Mining Sciences, 37 (2000) p. 801-818

[8] A. Saeidi, O. Deck and T. Verdel: Development of vulnerability functions in subsidence regions from empirical methods. Engineering Structure Journal, 31(10), (2009), P. 2275-2286.

[9] A. Saeidi, O. Deck and T. Verdel: Development of buildings vulnerability functions in subsidence regions from analytical methods. Géotechnique ;62(2) (2012), p.107-20.

[10] A. Saeidi: La vulnérabilité des ouvrages soumis aux aléas, mouvements de terrains: développement d'un simulateur de dommages. Doctorate thesis, Institut National Polytechnique de Lorraine, Nancy, France.(2010)

[11] M. Al Heib, J.P. Josien Y. El Shayeb: Paramètres d'affaissement pour la hiérarchisation des zones à risque dans le bassin ferrifère lorrain. Après -mines, Nancy.(2003)

[12] A. Abbass Fayad: Amélioration de code de calcul-Logiciel SUBSID : Application au cas des mines de fer. Rapport de DEA, INPL. (2000) 